\title{
Improving School Culture: What we Learnt from Three Primary Schools
}

\author{
Michael Gaffney, Jaleh McCormack, Nancy Higgins and Nicola Taylor \\ Children's Issues Centre, University of Otago, Dunedin.
}

\section{ABSTRACT}

This research article summarises a study that set out to collect information about the actions that three primary schools have taken to develop a more positive school culture. The aim was to identify in what ways a change in culture could contribute to an improvement in school relationships and a reduction in bullying.

The research questions focused on what the schools were like previously, how change was initiated, what programmes and community support were used, what the outcomes have been for adults and students, and what were the current challenges and goals that each school faced. A researcher was assigned to each school where they undertook interviews with a range of adults in the school and facilitated focus groups with students.

The results of the comparative analysis show that there are identifiable factors common to the approaches used by all three schools. These factors were the importance of leadership, the centrality of relationships, the nature of the programmes adopted, and finally, the nature of the change process itself. While there were many differences between the schools, these differences did not alter the relevance of the factors identified above.

\section{INTRODUCTION}

School culture is a relatively new concept in understanding schools as organisations. The development of the term began with anthropological understandings of schools and the way they work.

Neville (1998) used a case study approach to explore what it was that two New Zealand secondary schools were doing to achieve higher than expected outcomes for their students when other information about the schools indicated that this was going to be difficult to do. This study was able to identify why the schools were exemplary, and yet the same outcomes could not be achieved by using the structures and routines within these schools as a blueprint for other schools. That is, it was not a matter of student timetabling, departmental organisation, decision-making hierarchies or curriculum management and provision, but rather the quality of the leadership and interpersonal relationships within the schools. It was shown that this was because the structures and routines in the schools were the outcome of the schools' culture. This study identified the values that underpin the individual culture of two schools and gave their culture coherence.
But what is school culture? Stoll (2000) says that:

Culture describes how things are and acts as a screen or lens through which the world is viewed. In essence, it defines reality for those within a social organisation, gives them support and identity and creates a framework for occupational learning. Each school has a different reality or mindset of school life, often captured in the simple phrase, 'the way we do things around here' (p. 9).

A common set of understandings that form the basis of 'the way we do things around here' manifests itself across the school at different levels, from people's beliefs about teaching and learning to the practices and routines that develop into school systems and structures. Once some of these have been identified then researchers can look at how pervasive they are, how they support power relationships and to what extent they are interdependent (Pettigrew, 1990). Our interest in this project was to summarize the way things are done around here' to see if there are important understandings that can be gained from seeing how people went about changing 'the way things are done around here' and what implications it has for "how the way things are done around here' in the future.

There are other ways of understanding schools as organisations which have elements of overlap. Much of the focus is on how schools can change or be changed. For example, ideas such as quality schools (Doig, 2000), school improvement and school effectiveness (Rintoul \& Rosnowski, 2000), and schools as learning communities (Wenger, 1998). We chose school culture because it gave us a wide scope in describing where schools have been and where they are at rather than focussing on on school effectiveness that other frameworks use (Reichers \& Schneider, 1990).

We set out to explore the significant factors that influence a school's culture (also referred to as school ethos or school climate) that in turn can lead to, amongst other things, a reduction in the prevalence of bullying. Researchers should be able to identify the important school structures and routines that hold particular values and beliefs. We expect that these values and beliefs will also be reflected in the factors we identify as influencing the school culture (see MacArthur \& Gaffney, 2001; Sullivan, 2000). Our notion of what school culture includes is shown in the diagram below in Figure One. 
FIGURE ONE: School culture includes

\begin{tabular}{|} 
SCHOOL CULTURE \\
School structures and routines \\
School values and beliefs \\
Relationships between those in the school and \\
those outside of the school \\
Factors important to school change \\
\hline
\end{tabular}

This is still an oversimplification but it gives us a starting point. For example, we acknowledge that it is people that hold values and beliefs, and our interest is in how those values and beliefs come to typify the school. Likewise, there are issues of power when considering how values and beliefs are shared amongst those who make up a school. We have also avoided complicating matters by not looking directly at classroom culture, which also has important implications for how student's experience their school day (Macfarlane, 2004). That said, it is possible to see how school culture influences what goes on in the classroom.

\section{Research Aim}

The purpose of this study was to collect information about the approaches that three primary schools have taken to develop a more positive school culture, which as a result led to a reduction in bullying. In particular, the study examined the factors within each school that gave rise to a change in their school culture. This article summarizes a full report available from the Ministry of Social Development (Children's Issues Centre, 2004). It describes how the schools went about improving their school culture and identifies the similarities and differences in their approaches. The reason for sharing this information with other schools is to assist them in their own journey of school development.

This study was commissioned by the Ministry of Social Development to assist in implementing Action Area Four of New Zealand's Agenda for Children, which aims to address violence in children's lives with a particular focus on bullying. The Ministry was keen to see how improving school culture might reduce bullying in schools. It should be noted that reducing bullying is not the only reason that schools set out explicitly develop their school culture and this is the case in the schools presented in this article. We wanted to showcase schools that had successfully improved their school culture in a way that might provoke or support those wanting to facilitate change in other schools.

\section{METHOD}

\section{Description of Case Studies and Research Participants}

In Auckland, Wellington and Dunedin educational personnel (psychologists and RTLBs) who were familiar with schools in their regions were asked to identify a school that had changed its school culture in the past 2-3 years or more. Successful change was defined as improved outcomes in terms of student achievement, students' and teachers' social relationships (including a reduction in bullying), and parent and community opinion of the school. Evidence of this was likely to be anecdotal, but ERO reports written at the right time could support anecdotal evidence.

When agreement of the principal or board of trustees had been obtained for school participation the principal was asked to identify staff, Resource Teachers Learning and Behaviour (RTLB), Board of Trustees members, and external professionals who should be invited to participate. These participants were preferably those who had a long enough association with the school to see changes take place. Teaching staff identified students (8-12 years old) to be invited to participate in the study.

Each of the Boards of Trustees were asked to consider having their school named in the report. This they did on the basis that the research would be reporting a 'good news story'.

\section{Auckland - Papatoetoe Intermediate School}

This intermediate school (Years 7-8) in Manukau City has a current decile ranking of 3G. The school had a July 2002 roll of 977 students and 72 staff. Changes at Papatoetoe Intermediate School were initiated 10 years ago when the current principal joined the school.

\section{Wellington - Wilford Primary School}

Wilford is a full primary school (Years 1-8) in Lower Hutt with a decile ranking of 5M. The school had a July 2002 roll of 260 based on 11 classes, including two Maori immersion units. Changes began 9 years ago when the current principal joined the school.

\section{Dunedin - Caversham Primary School}

Caversham Primary is a contributing primary school (Years 1-6) in Dunedin. It had a July 2002 roll of 102 and has a decile ranking of $3 \mathrm{H}$. The current principal initiated the changes when she joined the school 4 years ago.

\section{Research Methods}

A qualitative approach enabled us to gather detailed information from a range of research participants within each school. Interviews and focus groups were chosen as an appropriate means of gathering detailed personal perspectives and experiences. These provided rich data for describing the actions taken, the process followed, the outcomes achieved, and the challenges faced in changing the school culture. Adult participants took part in an individual semi-structured interview at the school. Students took part in focus groups made up of 4-8 children who were of similar age, school level and represented a mix of gender and ethnicity. It should be acknowledged that in studying school culture researcher observation would usually be included. Because of funding and time constraints this was not undertaken.

\section{Analysis Framework}

The approach to analysis was for each researcher to develop an individual case study around the school they visited based on the data they had collected. For each school a profile was 
developed (Children's Issues Centre, 2004). Profile development included sending profiles back to the school to check for accuracy, interpretation and errors.

\section{FIGURE TWO: Framework for Collection and Analysis of Information}

\begin{tabular}{|c|c|c|}
\hline $\begin{array}{l}\text { Values, Beliefs, } \\
\text { Relationships \& } \\
\text { Systems }\end{array}$ & $\begin{array}{l}\text { History } \\
\text { What was changed? }\end{array}$ & $\begin{array}{r}\text { Values, Beliefs, } \\
\text { Relationships \& } \\
\text { Systems }\end{array}$ \\
\hline \multicolumn{3}{|c|}{ THE CHANGE PROCESS } \\
\hline \multirow[t]{4}{*}{$\begin{array}{l}\text { Initiation } \\
\text { of Changes }\end{array}$} & & $\begin{array}{l}\text { Implementation } \\
\text { of Changes }\end{array}$ \\
\hline & $\begin{array}{c}\text { Maintainance } \\
\text { of Positive School } \\
\text { Culture }\end{array}$ & \\
\hline & OUTCOMES & \\
\hline & $\begin{array}{c}\text { Including Community/ } \\
\text { Parent Response }\end{array}$ & \\
\hline
\end{tabular}

Analysis of the information drew on the elements within Figure Two. Additionally, this framework allowed for a comparative analysis of the resulting case study profiles. The key factors of beliefs, values, relationships and systems were considered in terms of history, change and outcomes. This is by no means a comprehensive list of possible approaches to examining culture, (Pettigrew, 1990), but covers many of the acknowledged factors.

\section{RESULTS}

In this article a comparative analysis across the three schools is made. There were some common factors identified across the schools. The four main factors from across the case studies that will be discussed here are:

- the importance of leadership in bringing about change

- the centrality of relationships to school culture

- the nature of the programmes that were used to bring about change

- the nature of the change process itself.

\section{Leadership}

Change was initiated in all three schools upon the appointment of a new principal. The principals, on coming into their new school, all identified a feature of the school culture that they believed should be changed. The areas identified differed across the three schools. At Papatoetoe Intermediate it was the high level of school suspensions and exclusions. At Wilford Primary it was the relative isolation of staff and the lack of collegiality. At Caversham Primary it was the overt level of violence in the playground. In all three schools the principal's starting point for change was maintaining the belief that school life did not have to be this way. Whereas many, if not most of those in the school had become accustomed to these features being part of school life.

A major sub-theme across the three schools was that individual teachers might be doing very well within their classrooms but it was the development of school wide practices that would be central to bringing about change across the school as a whole. The principals said it was their role to keep drawing the school's attention to the 'big picture'.

But within that there were teachers who were doing a remarkably good job. But I think by the time they had a classroom functioning they didn't have time or energy for the big picture. I didn't have a classroom so I came and got the big picture. (Principal, Caversham Primary School)

In support of this there were reports from research participants from all three schools about how the principals kept up with the latest research and ideas about learning and schooling. For example:

Oh yeah, right up to date with everything that was going on in education. I was reading stuff from the university training, actually if you went to discuss any of that stuff, which was right up to date stuff, with (the principal), she had read it. She knew it. She was way ahead of where we were, and we were supposed to be breaking new ground. (RTLB, Caversham Primary School)

All of the principals saw one of their leadership roles as identifying potential points for initiating change and bringing the staff 'on board' or getting their 'buy-in'. This meant that initial work within each school was with teachers and staff to develop a school wide vision and strategies to support the vision. In the two larger schools (Papatoetoe Intermediate and Wilford Primary) the Principals formally engaged the support of senior staff. At Papatoetoe Intermediate this was done by setting up a pastoral care team and at Wilford Primary it was the management team. In two of the schools part of the school wide work involved curriculum professional development. For the smallest school, Caversham Primary, this was done by bringing in outside advisors. At Wilford Primary, because of the principal's desire to build collegiality, time was made available for teachers to observe each other working in their classrooms.

One of the most powerful things we did was introduce David Stewart's 'Quality Learning Circles', [whereby] teachers go into each other's classes to learn, not to appraise that teacher but to learn. I released people and they formed three groups within the staff and they talked about what they were good at and what they wanted to learn and others said "well I would really like to come and see that". And even doing this was hard for some people, they found it quite difficult to talk to someone about themselves in positive terms, (Principal, Wilford Primary School). 


\section{The importance of relationships}

All three schools focused on developing and maintaining school wide approaches to the management of student behaviour. This involved staff in each school discussing as a group what it was that they were aiming for in terms of vision, the types of relationships they wished to have and the principles that would underpin such relationships. The key value identified by staff in each school to underpin the desired relationships was respect. At Wilford Primary staff were encouraged to focus on their own relationships first to improve collegiality. For staff at Caversham Primary the relationship focus was about teachers taking the initiative to model appropriate relationships for the students. At Papatoetoe Intermediate staff were asked to find ways to engage with more of the students. If students struggled to fit in at school then it was the school's responsibility to consider what could be done to support the students rather than using exclusions to remove them or suggest they go elsewhere.
... But teacher buy-in is not a given. It is a process that takes time and you can't just assume that teachers will understand and accept what we are trying to achieve here. We find that once they have been through our staff induction programme and become familiar with our approach that most of them do come on board. It may be easier in one sense to spend a minute and flick a kid on rather than spend ten minutes and try and help them resolve their problem. But it is the latter we promote here, not the former! (Principal, Papatoetoe Intermediate School)

The improvement in relationships between staff in all schools was a precursor to looking at the relationships between staff and students and between students. An important feature of improving student relationships was the setting of clear expectations. These expectations were promoted school wide as formal school rules, within school newsletters and at school gatherings. Staff were asked to model and promote the type of interactions seen as appropriate to the school. Consequences for appropriate and inappropriate behaviour were an essential means of reinforcing the expectations. Participants in this study from across the schools talked about making sure that staff were immediate, consistent and fair in their approach when responding to inappropriate behaviour.

When most students understand what is expected of them and know what the consequences will be for both appropriate and inappropriate behaviour they not only meet the expectations they sustain them. To this end at Wilford Primary School, while only some students are given the official role of peer mediator, all students are taught peer mediation skills.

Using the peer mediation model. I expect them to both agree to solve the problem. I expect them to tell the truth and not blame other people. I expect them to put themselves in other people's shoes and to generate a solution that is going to be acceptable to both parties. Quite often, because some of them are so skilled in this, they will come to me with a conflict, four or five of them and I will sit here, they do it, very quickly and off they go. (Principal, Wilford Primary School)

Change will not be successful if enforcement is from the adults only. For example, one principal said "the students could be a lot more sneaky about their violence ... because if a kid saw you they would stop being violent" (Principal Papatoetoe Intermediate School). Once students started reinforcing expectations and supporting consequences then violence and bullying can be dealt with.

Some of the older children at Caversham Primary described how they felt there had a been a big improvement in the way students interacted with each other.

Student: When I was about six years old, there was heaps of bullies here. Um They used to be on the tower. They used to fight and stuff. Used to be like a wrestling ring, they'd push everybody off.

\section{Researcher: Mmmm. So did it change over time? Is it better now?}

Student: Yep. Yep. It's changed. Dramatically. (student, Caversham Primary School)

In all three schools the students in the research talked about what the school or classroom rules were and knew what the consequences were for inappropriate behaviour in particular. The children generally reported that they liked being at school. They reported a sense of people caring and school being a safe place to be. Students also talked about what they should do if they saw a bullying incident developing.

\section{The programmes used to bring about change.}

A feature of the programmes in the case study schools was that there was not just one. In the case of Wilford Primary, the school developed an umbrella programme they called Promoting Positive Relationships under which other programmes were placed. The thinking and decision-making about how the programme operated was the responsibility of the principal and management team. At Papatoetoe Intermediate the pastoral care team, referred to earlier, provides overall direction for student welfare within the school. As other programmes are initiated by the team they may have their own teams set up with delegated responsibilities. At Caversham Primary, the school was small enough for change to be led by the principal without requiring separate teams or groups to be set up.

In looking at the range of programmes offered, the common focus across all them at each of the schools was the focus on supporting the well-being of students (and staff). A reduction in bullying or violent behaviour was only one of the outcomes associated with improving student well-being. All three schools recognised that student well-being, both 
physical and emotional, is a requirement for maximising teaching and learning opportunities. At Caversham Primary this includes providing food for some of the children. Research participants at all three schools talked about acknowledging the cultural diversity of the students within the school. Student ethnic identity and culture was supported and accepted.

[We] celebrate diversity. The positive about this school is there is no norm. So a lot of tension that goes on in other schools, doesn't happen because: "who's the norm?" "Where's the stereotype?" It doesn't exist. So your different culture, your body shape, your accent, how you look, what clothes you wear is just accepted. You can wear the hairstyle you like, what clothes you like. The clothes here vary hugely and no-one ever says anything. (Principal, Wilford Primary School)

Students made comments that indicated a sense of belonging to their schools.

We get lots of badges with the reward system - for being in orchestra, choirs, sports teams, road patrol, librarian. (Year 8 student, Papatoetoe Intermediate School)

Student 1: They always look after you when you get hurt.

Student 2: You're not bossed around.

Student 3: The best thing about Caversham School is when you come, you have friends and you don't feel lonely. (Students, Caversham Primary School)

Much of the support for students comes via programmes for individual students or small groups.

All three schools had participated in the Eliminating Violence - Managing Anger programme (commonly referred to as the Eliminating Violence programme ) offered by Specialist Education Services, now Ministry of Education, Special Education. When looking for schools to participate in this study we did look for schools that had participated in some form of anti-bullying programmes, but it was not known until later that all three had actually participated in the Eliminating Violence programme. This programme itself is not based on set content, but rather introduces an on-going process of whole school review with an external professional gathering data about what is happening in the school and then facilitating the school's development of a response to the information.

Professionals external to the school were important in the implementation of programmes such as the Eliminating Violence programme in which all three schools participated. Credible external or visiting professionals can have some influence with staff by bringing the outsiders more 'objective' view. This view is likely to validate the change leader's view.

It's good because I can preach whatever I like. I drive this, I am sure that I drive this and lead it, but it becomes like, "she thinks that, the Principal thinks that but what about the rest of the world". It is really powerful to bring other people from outside in who say the same thing in a different way. So we have done a lot of that, we've had School Support Services, Special Education, Peace Foundation in the early days. (Principal, Wilford Primary School)

Another group of professionals who can be called on at any time independent of a programme includes the public health nurses, the RTLBs or social worker in schools. These professionals provide on-going support to the schools over time.

\section{The change process}

Research participants, principals in particular, at all three schools commented on how developing the school culture they envisioned required lots of time and energy. Originally when looking for schools to participate in this study the aim was to find those that had been in the process for at least 2-3 years. In the case of Papatoetoe Intermediate and Wilford Primary both had initiated changes with a school culture focus that began 8-9 years ago, yet the principals reported that the time and energy required now is just as great as that needed at the beginning.

Keep it alive, keep all parties involved, keep looking at new and interesting and exciting innovations, keep looking at ways to celebrate successes, it's a huge amount of work, so when people say send me your package well I am afraid it doesn't work like that. This is the ninth year I have been here and I still see huge development to be done. (Principal, Wilford Primary School)

There does not appear to be a time when the programmes or the school culture sustains itself. This is particularly true of Papatoetoe Intermediate School where students are at the school for such a short time and there are always new staff to induct.

It can be difficult to induct new staff into the school's ethos and systems at times. We have a large staff with 50 classroom teachers. Five left in the first half of the year, and although this is felt keenly within the school, a $10 \%$ resignation rate is really quite low. However, it still means that five new teachers need to be inducted by the syndicate leaders and deans.

Many assemblies at the beginning of the year are driven towards getting the children on board with the pastoral care and discipline aspects within the school. These messages are then reinforced by each teacher within their classroom. Over the following fortnight they talk about respect and the other things we value, especially non-violence. The students then clearly know what we are aiming for here and why we have a counsellor, high expectations, discipline - rules and consequences. (Principal, Papatoetoe Intermediate School)

Another outcome that was reported by school staff beyond the reduction in bullying and improvement in behaviour is 
that teaching is easier. Classroom management and playground supervision is a more pleasant experience rather than a chore. Staff report there is more support available, issues can be talked through and teachers are not left to work out classroom management on their own. For staff this improves collegiality and for students school is a place where people care.

Well I think the strengths are the staff work together as a unit. We support each other and we have a real dedication to our children. The children are first you know. I think the staff here go looking for what they can do to help. They don't hide from it whatsoever. I think you only need to look at the phone calls that go in after school or weekends and things, just to check up on how this is happening and "can we help you here? And: get this meeting going." Or whatever. And they look at the children very much as individuals and not as a group of a particular year... And I think the staff getting on together is an important aspect too, to work as a unit, really. (Teacher, Caversham Primary School)

The students and teachers work together to create a pleasant environment in class and out of class - there is always someone who will respect you and make you feel good.

school is a safe, fun and a nice place to go to - you don't get up in the morning and say 'oh, I don't want to go to school' (Students, Papatoetoe Intermediate School)

\section{DISCUSSION}

In summary, the key feature in altering school culture in each of the schools was the leadership of the school principal in deciding that change was required. In each of the schools there were practices and behaviours with which the principals were not happy and those behaviours did not fit their view of a 'good'school. The road to change for all three principals involved developing a 'big picture', sharing it with their school's staff and then encouraging the staff to come on board and contribute to its realisation with the students.

One of the common approaches to developing the culture of each school was the implementation of a school wide system to supporting students to manage their behaviour (for further reading see NZCER, 2000). While this is the common terminology in schools, focusing on all school relationships advanced the discussion about how this was done. It was no longer about what adults did to students but about making it okay to talk about what kind of social environment people wanted and then agreeing how to share the responsibilities for making it happen. The adults in each school as well as the students were given opportunities to examine relationships within the school and decide how they would like them to be. This discussion was symbolised in the development of school rules and classroom agreements. The work was done collectively and expectations about the way in which everybody in the school should interact were formed. In order to help meet these expectations clear consequences and procedures were established within the school that acknowledged both appropriate behaviour and inappropriate behaviour. Achievements were celebrated and appropriate behaviour rewarded. Students who did not meet the expectations were not removed from the schools, but instead were provided with support and opportunities to learn how to interact within and through the school culture. These opportunities and supports made it possible for students and adults to succeed in changing the playground and classroom culture and contribute to the overall school culture. This process allowed adults and students to become committed to maintaining and improving the resulting school culture.

Across the approaches and strategies adopted by the three schools we can see a set of values and beliefs emerging that could be said to typify a good school. This would include the idea that schools should be positive environments for adults and students, where practices are inclusive. If students are struggling to establish good relationships and act appropriately then lots of support is given to them so they achieve these things. This reinforces a student's belonging to the community and the school community's responsibilities for their students. This is not to say that there will not be students who are eventually excluded from the community, but this happens only after every effort has been made and opportunities for change have been provided. Another value is one of ownership and participation by both adults and students. A principal may have an idea that things can be different, but it is only by getting the school staff, parents and students to collaborate in establishing what that difference may look like that sustainable change starts to occur.

These values are present even though the starting point for initiating change was based on the principals making a judgement about where to begin. At Papatoetoe Intermediate School it began with the introduction a pastoral care focus to better respond to the needs of their students rather than limit the focus to curriculum and discipline issues. At Wilford Primary School it was about improving collegiality amongst the staff and at Caversham Primary school it was about reducing school violence. The common theme across the different starting points was the focus on relationships. The common key value was the development of respect across school relationships.

Associated with a different starting point in each school was the diverse range of programmes implemented. The common feature that holds the different programmes together within the schools and makes them appear similar was the focus on improving student well-being of which the elimination of violence and bullying is only one part. The understanding being presented here is that frequent bullying within a school is the indirect or direct result of the school culture. Anti-bullying programmes that do not address the underlying aspects of school culture that support the occurrences of bullying are likely to fail. The positive message within this is that schools can address bullying by focusing on student well being. Once a school has developed 
a culture of supporting student well-being (a strength based model) then occurrences of bullying can be dealt with within a wider context of "This is the way things are done around here" (appropriate behaviour) rather than just a reaction to bullying (inappropriate behaviour).

An important feature of programme management was how the schools continued to monitor the success of their programmes and then drop, alter or add to them accordingly. Programme evaluation was done on the basis of people understanding how each programme contributed to their school and its community as a whole. This ongoing refinement of individual programmes supported the development of a more positive school culture and the realisation of each school's vision for itself. The reports from all project participants were that the schools became much better places for students and staff. But there is no sense of having 'finally got there' as on-going time and energy is required to sustain the culture of the schools and prepare for further development. Sustaining the culture of the schools required a recommitment to practices and beliefs each day.

\section{Implications}

The outcomes from the three schools does not necessarily offer a recipe that other schools must adopt for success. However, we would like to suggest that the principles of change identified in these three case study schools are critical for any school wanting to improve its school culture and reduce bullying. These principles are that:

1) leadership will be critical to initiating the change process, but staff support (buy-in), followed by student support, is needed to achieve school wide development;

2) the development of a more positive school culture will require people to look at the relationships that make up the school;

3) the programmes implemented, and it is unlikely to be just one, will in general need to focus on supporting the well-being of students in the school; and

4) the change process requires lots of time and energy and never becomes self sustaining.

The development that all three schools undertook, using the principles listed above, was a single school wide policy or approach to managing student behaviour and the promotion of positive relationships. Such a policy or approach included:

- creating clear expectations through discussion about what was considered as desirable school relationships and appropriate behaviour;

- setting in place consistent, immediate and fair consequences for both appropriate and inappropriate behaviour; and

- providing support for students (and adults) so they could develop positive relationships and learn to behave appropriately.

\section{Conclusion}

It is a challenge for any school to be able to provide a warm and friendly social environment for the purposes of supporting teaching and learning. Each of the schools in this project could respond to the challenges placed before them and were able to find and continue to look for solutions that worked for them. They, along with all the other schools that have taken up the challenge, now place the challenge before other schools to look at their own school culture and consider the way forward. The research team would like to acknowledge the good will shown by both adults and children in each of the schools when talking about topics that can be sensitive, especially in a context of schools agreeing to allow their names to appear in subsequent publications such as this one.

\section{REFERENCES}

Doig, C. (2000). Quality the Richmond way: Developing a successful behaviour management programme. Wellington: New Zealand Council for Educational Research.

Children's Issues Centre, (2004). Developing a more positive school culture to address bullying and improve school relationships. Wellington: Ministry of Social Development, July. (http://www.msd.govt.nz/work-areas/children-andyoung-people/agenda-for-children).

MacArthur, J. and Gaffney, M. (2001). Bullied and teased or just another kid? The social experiences of students with disabilities at school. Wellington: New Zealand Council for Educational Research.

Macfarlane, A. H. (2004) Kia hiwa ra! Listen to culture - Māori students' plea to educators. Wellington: New Zealand Council for Educational Research.

Ministry of Social Development (2002). New Zealand's Agenda for Children: Making life better for children. Wellington: Ministry of Social Development, June.

Neville, M. (1998). The teachers know my name: Two case studies of value-added secondary schools in New Zealand. Educational Research \& Development Centre, Massey University. Report to the Ministry of Education. April.

NZCER, (2000). Behaviour Management. SET: Research information for teachers (2), 19-43.

Pettigrew, A. M. (1990) Organizational climate and culture: Two constructs in search of a role. In B. Schneider (ed) Organizational Climate and Culture (pp.413-433). San Francisco: Jossey-Bass.

Reichers, A. E. \& Schneider, B. (1990) Climate and culture: An evolution of constructs. In B. Schneider (ed) Organizational Climate and Culture (pp.5-39). San Francisco: Jossey-Bass.

Rintoul, J. \& Rosnowski, J. (2000). The effects of school governance, ownership, organization and management on educational outcomes. Report to the Ministry of Education. Christchurch College of Education, April. 
Wenger, E. (1998). Communities of practice: learning, meaning and identity. London: Cambridge University Press.

Stoll, L. (2000). School Culture. SET: Research Information for Teachers, 3, 9-14.

Sullivan, K. (2000). The anti-bullying handbook. Auckland: Oxford.

Michael Gaffney has worked at the Children's Issues Centre, University of Otago as a researcher since its inception nine years ago. Jahleh McCormack has a background in geography and has worked in a number of education projects at the Children's Issues Centre before moving on to the Ministry of Social Development and then overseas. Dr Nancy Higgins has a background in disability studies and is now working as a research developer at the Dunedin College of Education. Nicola Taylor has a legal and social work background and has also worked at the Children's Issues Centre since its inception.

Contact: michael.gaffney@otago.ac.nz 